\title{
La alternancia estilistica de la lengua de Sancho en el episodio de la ínsula de Barataria
}

\author{
GUILLERMO SERÉS \\ Universidad Autónoma de Barcelona
}

\section{LOS TRES ESTILOS}

Como apuntaba en su día el homenajeado, «es diáfano que Cervantes está preocupado continuamente por la explotación estilística de la lengua» (Gutiérrez Cuadrado 2004: 843). Para confirmar sus palabras, es preciso recordar, sumariamente, las características de los tres estilos ${ }^{1}$ : (1) el humilde, bajo o ático estaba recomendado, por su sobriedad, para un discurso de género judicial y en cuya electio verborum se debían tener en cuenta palabras castizas y claras, «apropiadas» o de uso común, sin llegar a la grosería; o sea, debían ser decorosas y honestas, nunca soeces; tampoco se permitían solecismos, cultismos o metáforas excesivas. Es el estilo a que alude Cervantes en el prólogo al lector de la Primera parte del Quijote, cuando señala que va a
procurar que a la llana, con palabras significantes, honestas y bien colocadas, salga vuestra oración y período sonoro y festivo, pintando en todo lo que al- canzáredes y fuere posible vuestra intención, dando a entender vuestros con- ceptos sin intricarlos y oscurecerlos (p. 19)2.

También se recomendaba que el autor se abstuviese, o usase moderadamente, las simetrías o paralelismos sintácticos, los períodos plurimembres, las enumeraciones o las figuras de expresión que abundan en la similicadencia o en la anáfora; análogamente, estaban prohibidas las annonimationes, paranomasias y digresiones, porque los períodos debían ser breves y ágiles, acordes con la oratio soluta (véase nota 8). Un estilo suelto, sobrio y austero; cuajado de «gracejo en el decir» (facetia), con agudezas breves y puntuales, incluidos los refranes, obviamen-

Este estudio se inscribe en el marco del proyecto de investigación de la Generalitat de Catalunya: Grup de Recerca Consolidat TETSO (Transmisión y Edición de Textos del Siglo de Oro ), núm. expediente 2009 SGR 297.

${ }^{1}$ Que, por ejemplo, señaló Alfonso García Matamoros en suDe tribus dicendi generibus ; últimamente, los ha descrito muy bien Artaza (2006: 49-55). Cuatro si tenemos en cuenta que «en las dos últimas décadas del s. XVI se pone de moda otro estilo, el llamado lacónico, de frase breve, concisa, cargada de contenido» (Artaza 2006: 53); complétese con Egido (1996), y García López (2001).

${ }^{2}$ Avalle-Arce (1976: 13-35) nos previene de la «afectada modestia» del prólogo; véase también Menéndez Pidal (1991: 17-20 y 24-34).

Cita: Serés, Guillermo (2014): "La alternancia estilística de la lengua de Sancho en el episodio de la ínsula de Barataria”, en M. P. Garcés Gómez, M. Bargalló Escrivà y C. Garriga Escribano, eds., "Llaneza": estudios dedicados al profesor Juan Gutiérrez. Cuadrado, A Coruña, Universidade da Coruña, Anexos de Revista de Lexicografía, 23, pp. 539-556. https://doi.org/10.17979/spudc.9788497498012.539 
te. (2) Quintiliano caracteriza el estilo medio de brillante en las figuras, suave en las digresiones, adecuado en la compositio y placentero en los contenidos; sus períodos deben ser moderadamente largos, con incisos o excursos, y, eventualmente, paralelismos y antítesis sintácticas, desdoblamientos, congeries o hendíadis, o figuras relacionadas con la interpretatio (véase nota 13) así como las gradaciones, iteraciones, isocola y figuras análogas; su léxico es más abundante que el anterior. (3) El tercer estilo, el sublime o asiático, será abundante y grave, grandilocuente, vehemente, adornado; servirá, según Quintiliano, para mover los afectos, o sea, para tratar materias trascendentes y patéticas. A tal efecto, se recomendaba una buena electio verborum, acorde con la dignidad o gravedad del tema; la cita de aurea dicta; de nombres de los dioses y sus atributos; de varones ilustres, linajes, pueblos, gentilicios...; de virtudes, cargos, dignidades y de todo lo que incremente el pathos: lágrimas, suspiros, lloros, sangre...; en su compositio se requerían períodos largos y abundantes; le convenían todas las figuras de pensamiento y dicción, especialmente las que comportan patetismo: sermocinatio, interrogaciones retóricas, admiraciones, lamentos y, sobre todo, la fictio personae.

En el trabajo arriba citado, el admirado amigo Juan Gutiérrez Cuadrado seguía la estela de otros estudios, excelentes como el suyo, que han abordado esta cuestión: los de Menéndez Pidal, Morreale, Lapesa, Spitzer, Rosenblat o Hatzfeld. Con todo, apenas se ha considerado por qué salta Cervantes de un estilo a otro en el mismo fragmento o capítulo; por qué echa mano del medio, bajo o alto, consecutiva o simultáneamente, en función de las cambiantes situaciones narrativas; por qué alterna el uso «recto» y el paródico de cada uno en contextos similares. Por lo tanto, si la premisa mayor es que algunas prosas cervantinas muestran el conocimiento y la asimilación de los tres grandes estilos, que distribuye, dispone y dosifica apropiadamente, la menor es que en esa práctica Cervantes es especialmente brillante, porque consigue que alternen, simultánea o sucesivamente, al menos dos de los tres estilos, siempre que la mezcla o combinación léxica, o retórica, no afecte al decoro y sirva para enfatizar determinadas situaciones o caracteres. Especialmente en el Quijote, es capaz de pasar de un estilo a otro imperceptible o inadvertidamente ${ }^{3}$; de modo que el lector, casi sin sentirlo, subrepticiamente, se instala en el alto, el medio o el bajo, ya sea en su sentido recto, ya exagerado por la parodia. Y el lector no puede llevarse a engaño: distingue qué

${ }^{3}$ Cervantes «sí parece que se divirtió o disfrutó escribiendo del tal manera que el lector no notara su artificio, o lo hiciera con mucho esfuerzo»; por eso «las voces de los personajes, que parecen naturales, son productos de un artificio. La llaneza textual, la propiedad y, como resultado, la claridad, poco tienen que ver con la naturalidad lingüística» (Gutiérrez Cuadrado 2005: 360). 
es libresco y qué real o verosímil; qué responde a un patrón idealista y qué es un «documento», un «morceau de vie»; qué es sublime y qué cómico. Porque en muchos lugares del libro se pasa sin transición de un estilo a otro, de un género a otro, donde Cervantes yuxtapone un realismo de estilo bajo, que refleja la cotidianeidad más verista o «costumbrista» ${ }^{4}$, con recreaciones a lo «grand style» de novelas idealistas (caballeresca, pastoril, bizantina, sentimental...), de modo que, por contraste, aquella realidad se magnifica, se transforma, porque el lector la «lee» desde otro punto de vista: el que propicia, precisamente, aquella disposición simultánea de géneros, estilos y léxico ${ }^{5}$. Se completa así el proceso de desalegorización, en palabras de Aurora Egido ${ }^{6}$, porque, precisamente, se da aquella convivencia estilística o «entrecruzamiento» (al decir de Forradellas). En otras palabras, muy recientes, de Rico (2012: 18), a propósito del episodio del yelmo de Mambrino (I, 21):

la traccia ['huella'] del bacile ['bacía de barbero'] marca il cammino della quotidianità, sia che essa passi da una semplice fucina ['fragua'] de paese o dalle mani abili dello scudiero, che utilizzerà il recipiente per radersi in casa. Dalla poesia grandiosa degli elmi ['yelmos'] siamo passati alla storia minuta dei bacili, ma entrambe mantengono nel Chisciotte un dialogo permanente.

${ }^{4}$ En el contexto literario del Siglo de Oro, el término realismo debe usarse con todas las precauciones que recomienda López Grigera (1994: 138-139), al señalar que «no era la imitación directa de la realidad, ni como ideal ni como procedimiento, sino que se trataba ni más ni menos que del uso de varios recursos combinados de la retórica clásica y renacentista»; Close (1994: 101) ya prevenía de que el Quijote «reveal forms of mimesis remote from nineteenth Century empiricism [...] the theme of "la verdad de la historia" is that is not primarily to be understood as pointing to "realism" in a modern sense».

${ }^{5}$ A este particular son muy iluminadoras las palabras de Forradellas (2005: 290): «En el Quijote se mezclarán, partiendo de un mundo que parece procedente de la realidad observada, hechos e interpretaciones que la transforman en algo que está más allá de ella; lo caballeresco, lo cortés, lo pastoril o, incluso, lo picaresco, se intercalan en lo cotidiano; pero de pronto, en una inflexión estilística, inadvertida, se devuelve al lector a lo habitual. [...] Estos entrecruzamientos de los referentes que podríamos llamar realistas y los inverosímiles o literarios son nudos que propician la difuminación de fronteras, en una perspectiva problemática que es ya novela moderna». Todo esto lo hace caber en el género «historia», a cuya «falsificación» alude Blasco (1989: 51 53). Sobre la combinación de géneros, Riley (2001: 203-215).

${ }^{6}$ «La novela barroca inició, tras los pasos del Lazarillo, un proceso de desalegorización que cristalizó tanto en la picaresca como en la obra cervantina y que favoreció la mezcla genérica, lo mismo que la comedia. [...] El trasvase de temas, motivos y personajes o situaciones de una a otra fue enorme.» (Egido 1992: 24) o, como apunta Close (1994: 101), «the gloriously anarchic association of all kinds of literary representation — picaresque, pastoral, farcical, tragic, mythic — on a single supposedly quasi-historical plane». 
Ese dinámico diálogo permanente de géneros le sirve a Cervantes para dar énfasis estilístico, con calculada ambigüedad narrativa y con el preceptivo decoro, a una situación, un cambio de rumbo, una transición, una peripecia, e incluso una anagnórisis (como la que veremos abajo). Consigue así una prosa siempre cambiante, proteica, versátil, mediante la cual parece desmarcarse de los preceptistas, haciendo una apología de la libertad compositiva de la novela, fruto, precisamente, de su orfandad teórica ${ }^{7}$. Esa prosa, esa «escritura desatada» ${ }^{8}$, no significa poco rigurosa, sino discreta (Rosenblat 1971: 56-63), artística (Hatzfeld 1972: 212-225), variada (Menéndez Pidal 1991: 28) y, por más que parezca una contradicción, clara y natural (Gutiérrez Cuadrado 2005: 344-364), pues, aunque «desatada» traduzca el latino soluta, no vale «suelta» de los recursos retóricos; sí vale liberada de la rígida preceptiva que obligaba a la separación decorosa de los tres estilos para evitar la mutua «contaminación». Así parece desprenderse de fragmentos como el siguiente, perteneciente al episodio del gobierno de la ínsula, donde Cervantes alterna estilos y léxico altos y bajos (marco en negrita el predominantemente alto; en cursiva, el predominantemente bajo):

Dejamos al gran gobernador enojado y mohíno con el labrador pintor y socarrón, el cual, industriado del mayordomo, y el mayordomo, del duque, se burlaban de Sancho; pero él se las tenía tiesas a todos, maguera tonto, bronco y rollizo, y dijo a los que con él estaban, y al doctor Pedro Recio, que como se acabó el secreto de la carta del duque había vuelto a entrar en la sala: - Ahora verdaderamente que entiendo que los jueces y gobernadores deben de ser o han de ser de bronce para no sentir las importunidades de los negociantes, que a todas horas y a todos tiempos quieren que los escuchen y despachen, atendiendo solo a su negocio, venga lo que viniere; y si el pobre del juez no los escucha y despacha, o porque no puedeo porque no es aquel el tiempo diputado para darles audiencia, luego les maldicen y murmuran, y les roen los huesos, y aun les deslindan los linajes. Negociante necio, negociante menteca-

${ }^{7}$ «-Y siendo esto hecho con apacibilidad de estilo y con ingeniosa invención, que tire lo más que fuere posible a la verdad, sin duda compondrá una tela de varios y hermosos lizos tejida, que, después de acabada, tal perfección y hermosura muestre, que consiga el fin mejor que pretende en los escritos, que es enseñar y deleitar juntamente, como ya tengo dicho. Porque la escritura desatada destos libros da lugar a que el autor pueda mostrarse épico, lírico, trágico, cómico, con todas aquellas partes que encierran en sí las dulcísimas y agradables ciencias de la poesía y de la oratoria» (Quijote, I, 47, p. 602).

${ }^{8}$ Adapta la noción retórica de oratio soluta, no sujeta a reglas (en especial, métricas) predeterminadas, definida por Cicerón y Quintiliano (Institutio oratoria, IX, 4), donde distingue entre dos clases de estilo: uno bien soldado y conjuntado, y el otro característico de una composición desatada o suelta, como en la conversación: «oratio... soluta, qualis in sermone». Cf. Lausberg (1968: §981 ss.), Blasco (1989: 47 y passim); en general, López Grigera (1998). 
to 9 , no te apresures: espera sazón y coyuntura para negociar; no vengas a la hora del comer ni a la del dormir, que los jueces son de carne y de hueso y han de dar a la naturaleza lo que naturalmente les pide, si no es yo, que no le doy de comer a la mía, merced al señor doctor Pedro Recio Tirteafuera, que está delante, que quiere que muera de hambre y afirma que esta muerte es vida, que así se la dé Dios a él y a todos los de su ralea: digo, a la de los malos médicos, que la de los buenos palmas y lauros merecen.

Todos los que conocían a Sancho Panza se admiraban oyéndole hablar tan elegantemente y no sabían a qué atribuirlo, sino a que los oficios y cargos graves o adoban o entorpecen los entendimientos. Con esto quedó contento el gobernador y esperaba con grande ansia llegase la noche y la hora de cenar; y aunque el tiempo, al parecer suyo, se estaba quedo, sin moverse de un lugar, todavía se llegó el por él tanto deseado, donde le dieron de cenar un salpicón de vaca con cebolla y unas manos cocidas de ternera algo entrada en días. Entregose en todo, con más gusto que si le hubieran dado francolines de Milán, faisanes de Roma, ternera de Sorrento, perdices de Morón o gansos de Lavajos, y entre la cena, volviéndose al doctor, le dijo:

-Mirad, señor doctor, de aquí adelante no os curéis de darme a comer cosas regaladas ni manjares esquisitos, porque será sacar a mi estómago de sus quicios, el cual está acostumbrado a cabra, a vaca, a tocino, a cecina, a nabos y a cebollas, y si acaso le dan otros manjares de palacio, los recibe con melindre y algunas veces con asco. Lo que el maestresala puede hacer es traerme estas que llaman ollas podridas, que mientras más podridas son mejor huelen, y en ellas puede embaular y encerrar todo lo que él quisiere, como sea de comer, que yo se lo agradeceré y se lo pagaré algún día; y no se burle nadie conmigo, porque o somos o no somos: vivamos todos y comamos en buena paz compaña, ${ }^{10}$ pues cuando Dios amanece, para todos amanece. Yo gobernaré esta ínsula sin perdonar derecho ni llevar cohecho, y todo el mundo traiga el ojo alerta y mire por el virote, porque les hago saber que el diablo está en Cantillana y que, si me dan ocasión, han de ver maravillas. No, sino haceos miel, y comeros han moscas.

- Por cierto, señor gobernador — dijo el maestresala-, que vuesa merced tiene mucha razón en cuanto ha dicho. [...]

-Yo lo creo - respondió Sancho-, y serían ellos unos necios si otra cosa hiciesen o pensasen, y vuelvo a decir que se tenga cuenta con mi sustento y con el de mi rucio, que es lo que en este negocio importa y hace más al caso; y en si-

${ }^{9}$ Recuérdese que negociante vale por «mercader, comerciante», pero también «embaucador sin escrúpulos». Véase II, 47, p. 1009, y, en general, Fernández Gómez (1962).

${ }^{10}$ Posible referencia indirecta al juego de palabras vivamus / bibamus, que se puede encontrar en frases como «bibere humanum est, ergo bibamus» ['beber es humano; por lo tanto, bebamos']; «beati homines, quibus vivere bibere est» ['dichosos los hombres, para los que vivir es beber']; «bibamus, moriendum est» ['bebamos, que hemos de morir']; «beati hispani, apud quos vivere est bibere» ['felices los españoles, para quienes vivir es beber'], etc., etc. Cf. Cantera (2005: núms. 299, 316). 
endo hora, vamos a rondar, que es mi intención limpiar esta ínsula de todo género de inmundicia y de gente vagamunda, holgazanes y mal entretenida. Porque quiero que sepáis, amigos, que la gente baldía y perezosa es en la república lo mesmo que los zánganos en las colmenas. [...] ¿Digo algo o quiébrome la cabeza? (II, 49, pp. 1117-1120).

El fragmento es necesariamente extenso, para que se aprecie la proporción de los recursos y la alternancia estilística del texto previa a los capítulos en que me centraré.

\section{LA PERIPECIA INSUlAR DE SANCHO (QUIJOTE, II, 53-55)}

Por muy «desatada» que sea la escritura y muy contaminada estilísticamente, como acabamos de ver, en determinados momentos de la narración, como el que va a ocuparnos, aquella convivencia estilística, aquel diálogo genérico, están argumental, temática e ideológicamente motivados. En el episodio del final del gobierno de la ínsula (que se extiende principalmente a lo largo de los capítulos 53-55 de la Segunda parte), las escenas del ficticio gobierno de la ínsula de Barataria, de la vuelta del exgobernador a la realidad y a la historia (simbolizada con el reencuentro con Ricote), y de su posterior caída en la sima - que unas ruinas tapaban- en los aledaños del palacio están significativamente marcadas por los tres estilos (respectivamente, alto, bajo y medio), cuyo predominio alternante, recto o paródico, da fe de la pericia retórica de Cervantes. Con el cambio de estilo, subrepticio o evidente, subraya tres graves decisiones de Sancho: desengañarse del ficticio cargo, volver al ser «natural» de antes y tomar conciencia moral e «histórica». Análogamente, pasa de un espacio de la representación (la ínsula, el palacio ducal), o «literario», a otro real: el encuentro con el morisco y la caída en la sima; allí actúa (como escudero o gobernador), aquí es él mismo (campesino vecino de Ricote). A pesar de que ninguno de los tres estilos es «puro»—-por lo que decía de la «escritura desatada»—, estos cambios o transiciones se pueden sintetizar estilísticamente así:

- Estilo alto: enfatiza que de la realidad ficticia del palacio Sancho «asciende» estilísticamente a la ficticia y literaria ínsula de Barataria, con la posterior peripecia del descenso o «caída de príncipes» (II, 53)

- Estilo bajo: caracteriza la salida del gobierno de la ínsula y el encuentro con la «realidad» real y con la historia, mediante la consiguiente anagnórisis (II, 54) - Estilo medio: subraya el descenso a la sima real y el posterior ascenso a la realidad ficticia del palacio (II, 55).

A tenor del esquema, los respectivos recursos retóricos que señalaré en seguida enfatizan, por contraste, la parodia que impregna la deriva del escudero en los 
capítulos II, 53-55, subrayando sus desdichas cortesanas y la degradada situación a que ha llegado. Cervantes se vale de ellos para marcar discursivamente la distancia que se ha abierto entre el Sancho gobernador de pega (II, 53) y el que en breve asumirá un compromiso moral (II, 54). La posterior y accidentada vuelta del escudero al palacio ducal —o sea, al terreno de la representación— no está exenta de otra 'caída' en la impostura y ficción, de otro purgatorio irónico, simbólicamente subrayado por el brusco descenso a la sima (II, 55). A fin de enfatizar la alternancia entre ascenso y descenso, autenticidad y parodia, realidad y ficción (doble: el palacio ducal y la ínsula), recurrirá Cervantes al contraste entre las respectivas figuras de expresión de los estilos alto y el bajo y medio. Aquellas tienen su fundamento en la duplicación léxica o sintáctica (paralelismos, quiasmos, estructuras bimembres, etc. $)^{11}$, y a los recursos formales directamente emparentados con lo que en lingüística se suele llamar binomio léxico, desdoblamiento, pareja de sinónimos, iteración sinonímica y similares ${ }^{12}$, que en retórica suelen agruparse bajo las etiquetas de sinatroísmo, pleonasmo, hendíadis, congeries, e incluso interpretatio $^{13}$. Estos recursos, otros afines y demás técnicas emparentadas (como la annominatio) caracterizaron especialmente la prosa «culta» del siglo $\mathrm{XV}^{14}$, la

${ }^{11}$ Hatzfeld (1972: 212-225) señala tres grandes rasgos: acumulación, gradación y repetición, y recuerda que «también Sancho tiene sentimientos a que dan suelta tales acumulaciones enfáticas» (ibid.: 213).

${ }^{12} \ll$ Las tradicionales parejas [de palabras] que en ciertos pasajes del Quijote menudean, recuperando su vasta función expresiva, tan favorecida en el siglo XVI, Cervantes no las usa por hábito como otros, sino que en su tan variado estilo, suelen aparecer para matizar momentos de particular interés o emoción». Subraya más abajo que «la Segunda parte del Quijote, comparada a la Primera, representa el mayor grado de acendramiento a que llegan en este período los estilos del período precedente» (Menéndez Pidal 1991: 28-29 y 65); Rosenblat (1971: 116-130), por su parte, lo llama, genéricamente, sinonimia, (y «sinonimia glosada», (ibid.: 122), señalando que «es más bien recurso de encarecimiento, de claridad o de realce expresivo, sobre todo de intención burlesca. O responde a un sentido rítmico» (ibid.: 121); trae muchos ejemplos (ibid:: 119-120) y recuerda que la más general es la bimembre, «y no se limita al desfile de parejas de palabras, sino que puede ser también de frases y modos adverbiales; [...] otras veces es trimembre» (ibid.: 123).

${ }^{13}$ Véase, en general, Lausberg (1983: S9 406, 649-56, 667 y 751); para la interpretatio en concreto, la Rethorica ad Herennium, IV, XXVIII, 38. Durante la Edad Media, la definición depende en gran medida de San Isidoro, quien la ve como una especie de glosa que subsana la oscuridad de ciertos vocablos: «glossa Graeca interpretatione lingua sortitur nomen» (Etimologías, I, xxx, 1). De la congeries también se ocupa Rosenblat (1971: 123-130).

${ }^{14}$ Cuyos autores buscan «amplitud y magnificencia desarrollando las ideas de manera reposada y profusa, y repitiéndolas a veces con términos equivalentes [...] el pensamiento se distribuye en cláusulas simétricas y contrapuestas» (Lapesa 1980: 208). 
caballeresca y las traducciones, especialmente las de los clásicos grecolatinos ${ }^{15}$; evidentemente, tampoco dejaron de utilizarse durante todo el Siglo de Oro ${ }^{16}$. En mayor o menor medida, simples o mixtas, las encontramos en el estilo alto y medio; el bajo responde a un tratamiento diametralmente opuesto, como tendremos ocasión de ver.

\section{ARRANQUE CON EL ESTILO ALTO}

En II, 53, cuando el fingido gobernador de Barataria decidió abandonar el cargo y las intrigas palaciegas, las palabras que dirigió al asno sonaron sospechosamente falsas, o auténticamente paródicas:

—Venid vos acá, compañero mío y amigo mío, y conllevador de mis trabajos y miserias: cuando yo me avenía con vos y no tenía otros pensamientos que los que me daban los cuidados de remendar vuestros aparejos y de sustentar vuestro corpezuelo, dichosas eran mis horas, mis días y mis años; pero después que os dejé y me subí sobre las torres de la ambición y de la soberbia, se me han entrado por el alma dentro mil miserias, mil trabajos y cuatro mil desasosiegos. (1162).

A la posible cita, paródica, del conocidísimo y muy imitado primer verso («Benedetto sia 'l giorno e 'lmese et l'anno») del soneto LXI del Canzoniere de Petrarca (en negrita), únanse los recursos subrayados en cursiva: dobletes («compañero. . . y amigo»; «trabajos y miserias»; «de la ambición y de la soberbia»), incluso trípticos («miserias, trabajos, desasosiegos») o paralelismos («remendar... sustentar. .. »; «os dejé y me subí»). Señalo en cursiva los típicos binomios léxicos o desdoblamientos, sean o no sinónimos — la repetición de locuciones que permiten ampliar los períodos- porque tales eran el modus interpretandi que facilitaba la copia dicendi y los recursos que esperaba encontrar cualquier lector contemporáneo en tan 'grave' libro, que genérica y muy rápidamente suelen denominarse desdoblamientos, léxicos, conceptuales (congeries) y, a veces, sintácticos (propiamente interpretationes). Están integrados sea por la yuxtaposición de un cultismo $\longrightarrow$ un latinismo- y un vulgarismo $\longrightarrow$ un coloquialismo-, sea por la de dos términos de parejo estatuto lingüístico. También encontramos la fictio personae, los lamentos que incrementan el patetismo requerido en esa circunstancia y, claro, la electio de palabras dignas y graves. Al poco, vuelve por esos fueros retóricos, pero contrastados con un referente real: su

\footnotetext{
${ }^{15}$ Véase especialmente Gutiérrez Cuadrado (1993); puede comprobarse su aplicación me-
} tódica y práctica en Serés (1997).

${ }^{16}$ Cf. Morreale (1959: I, 46-48), y Azaustre (1996). Para la amplificatio «afectiva», Díaz Marroquín (2008). 
anterior condición de campesino, especialmente enfatizada con los recursos y estilo arriba citados, que marco de nuevo en cursiva:

-Abrid camino, señores míos, y dejadme volver a mi antigua libertad: dejadme que vaya a buscar la vida pasada, para que me resucite desta muerte presente. Yo no nací para ser gobernador, ni para defender ínsulas ni ciudades de los enemigos que quisieran acometerlas. Mejor se me entiende a mí de arar y cavar, podar y ensarmentar las viñas que de dar leyes ni de defender provincias ni reinos [...] Mejor me estáa mí una hoz en la mano que un cetro de gobernador; más quiero hartarme de gazpachos que estar sujeto a la miseria de un médico impertinente [...]; y más quiero recostarme a la sombra de una encina [...] que acostarme con la sujeción del gobierno. [...] Vuestras mercedes se queden con Dios, y digan al duque mi señor que desnudo nací, desnudo me hallo: $n i$ pierdo ni gano; quiero decir que sin blanca entré en este gobierno, y sin ella salgo, bien al revés de como suelen salir los gobernadores de otras ínsulas. (II, $53,1163)^{17}$.

El pretexto y la ocasión para echar mano de estos recursos retóricos parecen estar relacionados y subrayar la peripecia, marcada con «la presteza con que se acabó, se consumió, se deshizo, se fue como en sombra y humo el gobierno de Sancho» (II, 53, 1159, cursiva mía). O sea, vendrían a ser el correlato objetivo de su caída ${ }^{18}$, recuerdo real y paródico a su vez de las «caídas» de príncipes, nobles o «varones ilustres», tan difundidas a fines de la Edad Media: basta recordar el celebérrimo De casibus virorum illustrium, de Boccaccio. Puesta en boca de Sancho, o del narrador, que quiere personificar dichas caídas de príncipes en el caído gobernador de Barataria, supone un ejercicio de impecable ironía, de grave antífrasis por la baja condición del protagonista caído. Cervantes empieza a recordar —real o paródicamente - aquellos procedimientos y estilo con una iteración sinonímica (los verbos y predicados verbales en cursiva arriba citados: se acabó, se consumió. . .), a partir de un motivo de origen bíblico: «defecerunt sicut fumus dies mei» (Salmos, 101, 4).

${ }^{17}$ La frase de la antepenúltima línea ya la había pronunciado en la Primera Parte (I, 25, 273); es una reminiscencia de un lugar bíblico: «nudus egressus sum de utero matris meae, et nudus revertar illuc» (Job, 1, 21), como estudia Bañeza (1989). Gutiérrez Cuadrado (2005: 362), abunda en la naturalidad lingüística de Sancho al referirse a un pasaje parecido: «no parece fácil admitir que este discurso pertenezca al modo natural de expresarse un escudero campesino como Sancho... El lector queda convencido de que ha oído a un iletrado y no a un clérigo. La habilidad de Cervantes ha sido poner en boca de Sancho las palabras del predicador y hacer creer a muchos lectores que la expresión de Sancho es llana y apropiada».

${ }^{18}$ Así, como «caída», lo interpreta Riley (1990: 150). Sobre las «caídas» del Quijote en general, Urbina (1994: 96). 


\section{UN INTERLUDIO EN ESTILO BAJO}

En el capítulo 54 de la Segunda parte, Sancho Panza, después de abandonar el gobierno de la ínsula, se cruza casualmente con un antiguo paisano y amigo, el morisco Ricote, y sus compañeros de camino alemanes, todos embutidos en hábitos frailunos. Aquel, alborozado, le reconoce y Sancho completa la anagnórisis:

— ¿Válame Dios! ¿Qué es lo que veo? ¿Es posible que tengo en mis brazos al mi caro amigo, al mi buen vecino Sancho Panza? Sí tengo, sin duda, porque yo ni duermo ni estoy ahora borracho. [...]

Entonces Sancho le miró con más atención y comenzó a rafigurarle, y finalmente le vino a conocer de todo punto y, sin apearse del jumento, le echó los brazos al cuello y le dijo:

- ¿Quién diablos te había de conocer, Ricote, en ese traje de moharracho que traes? Dime quién te ha hecho franchote y cómo tienes atrevimiento de volver a España, donde si te cogen y conocen tendrás harta mala ventura. (pp. 11671168)

Las palabras castizas («borracho», «franchote», «moharracho»...) y las de uso común dan una impregnación costumbrista al fragmento, sin caer en la torpeza ni recurrir a términos soeces. Tampoco encontramos paralelismos ni construcciones plurimembres ni digresiones, sino frases ágiles y descripciones funcionales. Cervantes destierra aquí aquellos recursos del estilo alto y opta por la evidentia del llamado realismo. Más abajo los personajes se desnudan, se quitan los respectivos disfraces y se muestran tal cual son y con jovial realismo, comen y beben en el suelo de lo escaso que traen en las alforjas:

Arrojaron los bordones, quitáronse las mucetas o esclavinas y quedaron en pelota, y todos ellos eran mozos y muy gentileshombres, excepto Ricote, que ya era hombre entrado en años. Todos traían alforjas, y todas, según pareció, venían bien proveídas, a lo menos de cosas incitativas y que llaman a la sed de dos leguas. Tendiéronse en el suelo y, haciendo manteles de las yerbas, pusieron sobre ellas pan, sal, cuchillos, nueces, rajas de queso, huesos mondos de jamón, que si no se dejaban mascar, no defendían el ser, chupados. [...] Pero lo que más campeó en el campo de aquel banquete fueron seis botas de vino, que cada uno sacó la suya de su alforja: hasta el buen Ricote, que se había transformado de morisco en alemán o en tudesco, sacó la suya, que en grandeza podía competir con las cinco. (p. 1168)

La única annonimatio (en cursiva) es que «campeen» las botas (y no las espadas), sacadas de las alforjas, no de las vainas, por hombres iguales en condición, sin barreras religiosas, ni identidades vestimentarias o de nación; una annonimatio que subraya el contraste con los remilgados cortesanos, con sus respectivas 
libreas, de la falsa Barataria. Por lo mismo, Sancho ya no habla ni se conduce con el falso decoro de gobernador:

Todo lo miraba Sancho, y de ninguna cosa se dolía, antes, por cumplir con el refrán que él muy bien sabía de «cuando a Roma fueres, haz como vieres», pidió a Ricote la bota y tomó su puntería como los demás y no con menos gusto que ellos. Cuatro veces dieron lugar las botas para ser empinadas, pero la quinta no fue posible, porque ya estaban más enjutas y secas que un esparto, cosa que puso mustia la alegría que hasta allí habían mostrado. De cuando en cuando juntaba alguno su mano derecha con la de Sancho y decía:

Español y tudesqui, tuto uno: bon compaño.

Y Sancho respondía:

- iBon compaño, jura Di!

Y disparaba con una risa que le duraba un hora, sin acordarse entonces de nada de lo que le había sucedido en su gobierno, porque sobre el rato y tiempo cuando se come y bebe, poca jurisdición suelen tener los cuidados. Finalmente, el acabársele el vino fue principio de un sueño que dio a todos, quedándose dormidos sobre las mismas mesas y manteles: solos Ricote y Sancho quedaron alerta, porque habían comido más y bebido menos. (pp. 1169-1170)

El narrador, por consiguiente, opta por una electio verborum acorde: refranes, adjetivos con gracejo y sustantivos coloquialmente evidentes («mustias», «enjutas», «secas», «esparto»...), prevaricaciones lingüísticas en lingua franca ${ }^{19}$, destierro de los paralelismos, sinatroísmos y cualquier tipo de interpretatio.

La conversación, la comida, la confraternización con Ricote y sus compañeros y otras circunstancias del revelador encuentro hacen que Sancho asuma — según juicio mayoritario de la crítica- un compromiso moral, que se sustancia en el rechazo definitivo de sus anteriores función de gobernador e identidad ficticia -impuestas por los Duques y sus cómplices—, en el consiguiente autoconocimiento que ha ido alcanzando progresivamente el escudero y en la vuelta al «orden natural» y a la realidad histórica debidamente contextualizada, que narrativamente se refleja retomando —otra vez en compañía de don Quijote— la lógica narrativa de la novela ${ }^{20}$. Cervantes lo ha plasmado en un estilo ático, sobrio, que rezuma franqueza y que, acorde con el género judicial al que se asocia, da cuenta de una importante decisión moral.

${ }^{19}$ En la «lingua franca» que utilizan Ricote y sus compañeros alemanes ya apreció un signo de fraternidad Spitzer (1955: 170-171).

${ }^{20}$ El encuentro con Ricote como culminación de un línea moral cervantina lo explica Forcione (1988: 1038-1043); sobre la caracterización general de Sancho en este capítulo, es pertinente la revisión bibliográfica de Urbina (1982); Peset (2010: 125) señala la contradicción de que, «tras la gobernación, sus discursos lo convierten en un modelo de autoridad, pero también en burla de ella». 


\section{REMATE CON EL ESTILO MEDIO}

Frente al sentido propósito de enmienda y sincera convicción de Sancho Panza, tras su desengaño «político» y posterior encuentro con Ricote, y precisamente para subrayar la distancia moral con la precedente e impostada condición de gobernador de Barataria ${ }^{21}$, en II, 55, Cervantes usa predominantemente el estilo medio, que, además de exornar retóricamente la prosa, servirá para manifestar y denunciar el contraste entre el hipócrita (y originariamente libresco) mundo de apariencias que acaba de dejar y la realidad, representada por Ricote y su contexto. Como aconseja Matamoros, echa mano de los paralelismos, antítesis sintácticas, congeries, interpretationes y otros recursos de la copia dicendi ${ }^{22}$, como se aprecia en los cuatro binomios léxicos que encontramos ya al principio:

llegó media legua dél [del castillo del Duque], donde le tomó la noche, algo escura y cerrada; pero como era verano, no le dio pesadumbre, y así, se apartó del camino [...] y quiso su corta y desventurada suerte que, buscando lugar donde mejor acomodarse, cayeron él y el rucio en una honda y escurísima sima que entre unos edificios muy antiguos estaba [...] dio fondo el rucio, y él se halló encima dél, sin haber recebido lisión ni daño alguno. (II, 5, 1175-1176, cursiva mía)

En cualquiera de los casos, las equivalencias semánticas suelen ser contextuales y el significado conjunto se superpone al individual de cada término de la fórmula binaria. ${ }^{23}$ Predominan las parejas de cultismo más coloquialismo o equivalentes, de modo que se justifica la etiqueta de estilo medio por los paralelismos, desdo-

${ }^{21}$ Lo que no implica que Sancho no cumpliera bien su cometido y función; al contrario, es un excelente gobernador y, por tanto, administrador de justicia, como recuerda Allen (1979:19-36 y 98-100), estableciendo una analogía entre la carrera caballeresca de don Quijote y la de Sancho como gobernador, hasta tal punto, que Maravall (1976: 216-226) aplica el concepto de utopía en este episodio. En general, Urbina (1991: 73-74 y 181-182).

${ }^{22}$ Como indica Morreale (1959: 46), y señala que cumple otra función: es «medio para circunscribir las palabras del original y para aclarar los conceptos». Rosenblat (1971: 130-146) agrupa estos procedimientos bajo el epígrafe «repetición deliberada», con que define genéricamente las tradicionales «anáfora, epífora, complexión, anadiplosis, epanadiplosis, concatenación o clímax, diáfora, antanaclasis, etc. » (ibid.: 131); trae muchísimos ejemplos. Más abajo se refiere a «la repetición con antítesis» (ibid:: 141) y a la gradación (ibid.: 146).

${ }^{23} \mathrm{Al}$ decir de Gutiérrez Cuadrado (1993: 341), dichos términos se pueden diferenciar «por la extensión semántica distinta (concreto / abstracto; general / particular...); o por pertenecer a registros distintos o expresar connotaciones claramente diversas: culto / popular; término integrado o tradicional / neologismo (derivado, préstamo, calco); lengua común / lengua de especialidad...»; un poco más abajo añade que «los sinónimos de diccionario no suelen aparecer, normalmente, en la misma duplicación». 
blamientos, hendíadis, o figuras relacionadas con la interpretatio. Sirvan las siguientes muestras, que señalo en cursiva, indicando las páginas respectivas:

—las halló [las paredes] rasas y sin asidero alguno, de lo que Sancho se congojó mucho.

—el rucio se quejaba tierna y dolorosamente; y no era mucho, ni se lamentaba de vicio

— mandando a sus sirvientes y a sus vasallos

— in haber persona alguna [...] ni criado ni vasallo que acuda a su socorro

- si ya no nos morimos antes, él de molido y quebrantado, y yo de pesaroso

—como lo fue mi señor don Quijote [...] cuando descendió y bajó a la cueva

—no parece sino que se fue a mesa puesta y a cama hecha

-Allí vio él visiones hermosas y apacibles y yo veré aquí, a lo que creo, sapos y culebras. (1176)

—Desdichado de mí, y en qué han parado mis locuras y fantasías!

—no ha querido nuestra [...] suerte que muriésemos en nuestra patria y entre los nuestros

— Oh compañero y amigo mío, qué mal pago te he dado de tus buenos servicios!

- tal era el aprieto y angustia en que el pobre se hallaba,

- habiendo pasado toda aquella noche en miserables quejas y lamentaciones,

—vino el día, con cuya claridad y resplandor vio Sancho que era imposible [...] salir

—comenzó a lamentarse y dar voces, por ver si alguno le oía (1177)

—descubrió [...] un agujero, capaz de caber una persona, si se agobiaba y encogía

—e entró por él, y vio que por de dentro era espacioso y largo

-Vio también que se dilataba y alargaba por otra concavidad.

- $A$ veces iba a escuras, y a veces sin luz; pero ninguna vez sin miedo

—Él si que tuviera estas profundidades y mazmorras por jardines floridos y por palacios de Galiana

—esperaba salir de esta escuridad y estrecheza a algún florido prado

— pero yo sin ventura, falto de consejo y menoscabado de ánimo,

-Vuelve a tratar de don Quijote, que alborozado y contento, esperaba el plazo

—a quien pensaba enderezar el tuerto y desaguisado que malamente le tenían fecho. (1178)

—aliéndose [...] a imponerse y ensayarse en lo que había de hacer

—dando un repelón o arremetida a Rocinante, llegó a poner los pies tan junto

a la cueva

— pudo percebir y entender que el que las daba [las voces] decía

—Pareciole [...] que oía la voz de Sancho Panza, de que quedó suspenso y asombrado 
- Sancho Panza, gobernador, por sus pecados y por su mala andanza, de la ínsula

— pues es mi profesión favorecer y acorrer a los necesitados deste mundo, también lo será para acorrer y ayudar a los menesteroso $s$ del otro mundo

—el que profesó socorrer y ayudar en sus necesidades a los vivos y a los muertos (1179)

— habiendo dejado mi gobierno por cosas y causas que es menester más espacio para decirlas

-Finalmente, como dicen, llevaron sogas y maromas (1180)

-Dios sabe lo mejor y lo que le está bien a cada uno (1181)

$\longrightarrow$ si sale pobre [de su gobierno], que ha sido un parapoco y un mentecato (1182)

- yo he tanteado las cargas que trae consigo, y las obligaciones, el gobernar (1182)

— mandó que le regalasen, porque daba señales de venir mal molido y peor parado. (1183)

También incorpora algunos trípticos, casi siempre iteraciones sinonímicas, como la citada arriba: «viéndose bueno, entero y católico de salud, no se hartaba de dar gracias a Dios» (1176); «de aquí sacarán mis huesos [...] mondas, blancos y raídos» (ibid.); «como sale este pecador del profundo abismo: muerto de hambre, descolorido, y sin blanca a lo que yo creo» (1181). Lo mismo cabe decir de los paralelismos sintácticos, las cláusulas bimembres o recursos afines:

-el que ayer se vio entronizado gobernador de una ínsula [...] hoy se había de ver sepultado en una sima (1176)

- i...ya que no hallara remedio nuestra desgracia, no faltara quien dello se doliera, y en hora última de nuestro pasamiento nos cerrara los ojos!

— prometo de ponerte una corona de laurel [...] y de darte los piensos dobla$\operatorname{dos}(1177)$

- ¿Hay algún cristiano que me escuche, o algún caballero que se duela de un pecador enterrado en vida, de un desdichado desgobernado gobernador?

— ¿Quién está allá abajo? ¿Quién se queja? -¿Quién puede estar aquí, o quién se ha de quejar...?

- se le dobló la admiración y se le acrecentó el pasmo

— por eso acaba de declararte y dime quién eres. (1179)

-El rebuzno conozco [...] Y tu voz oigo, Sancho mío. (1180)

- ni he tenido lugar de hacer cohechos, ni de cobrar derechos

- No te enojes, Sancho, ni recibas pesadumbre de lo que oyeres

$-\mathrm{y}$ es querer atar las lenguas de los maledicientes lo mesmo que querer poner puertas al campo 
- Si el gobernador sale rico de su gobierno, dicen dél que ha sido un ladrón; y si sale pobre, que ha sido un parapoco y un mentecato. (1181)

- ni son peso de mis costillas, niflechas de mi aljaba

—No he pedido prestado a nadie, ni metídome en granjerías (1182)

Incluso se puede entresacar algún quiasmo:

—nunca Sancho Panza se apartó de su asno, ni su asno de Sancho Panza? (1177)

- Esta que para mí es desventura, mejor fuera aventura para mi amo don Quijote (1178)

—en ellos me han perseguido médicos, y enemigos me han brumado los güesos

—en la cual [ínsula] entré desnudo y desnudo me hallo: ni pierdo ni gano y así, antes que diese conmigo al través el gobierno, he querido yo dar con el gobierno al través (1181)

No deja de ser muy significativo que estas dispositiones lingüísticas y recursos retóricos aparezcan tan abundantemente en II, 55, un capítulo «de transición» entre la gobernación y la falta de poder, donde un Sancho desposeído de la ínsula, y literalmente tragado por la tierra (el exgobernador de Barataria y el rucio caen en la gruta que comunica con el castillo de los Duques), reniega de su anterior estado y quiere «regenerarse», recuperar su identidad, dejar de ser una sombra de sí mismo y, por lo tanto, salir de la simbólica «caverna platónica» ${ }^{24}$. Es su particular cueva de Montesinos ${ }^{25}$, su peculiar descenso a los infiernos (Moner 1994: 854-856.). Otros estudiosos, en fin, creen que la caída es como una purgación, o como una permanencia en el purgatorio, que permitirá al escudero pasar a una vida nueva ${ }^{26}$. Simbolismos aparte, estamos ante una reelaboración paródica de algunos lugares comunes, como subraya el tono lastimero y la interrogación retórica que recuerdan las fórmulas del tópico del ubi sunt? Y que, como aquí paródicamente ocurre, se usaban especialmente para referirse a las «caídas» de reyes y de otros grandes de la tierra. Así lo apunta el propio Sancho en un monólogo,

${ }^{24}$ Marasso (1954: 232-333) fue quien relacionó, paródicamente, la estancia de Sancho en la gruta con la caverna de la República de Platón, representada por el gobierno de la ínsula.

${ }^{25}$ El paralelismo con la cueva de Montesinos (Quijote, II, 22-23) lo indica el propio Sancho: «a lo menos no seré yo tan venturoso como lo fue mi señor [...] cuando descendió y bajó a la cueva de aquel encantado Montesinos [...] Allí vio él visiones hermosas y apacibles, y yo veré aquí, a lo que creo, sapos y culebras» (II, 55, 1077-78); ya lo estudió Lida (1956: 422), subrayando que Sancho, con razón, piensa que es más propia de su amo que de él.

${ }^{26}$ Así parecen interpretarlo Casalduero (1975: 332-335), y Percas de Ponseti (1975: 630637). 
impropio de su lengua y cultura, en el que volvemos a encontrar recurrencias paralelísticas:

¿Quién dijera que el que ayer se vio entronizado gobernador de una ínsula, mandando a sus sirvientes y a sus vasallos, hoy se había de ver sepultado en una sima, sin haber persona alguna que le remedie, ni criado ni vasallo que acuda a su socorro? (II, 55, 1176)

A continuación, los poco cervantinos adjetivos pesaroso y venturoso (menos apropiados aun en boca de Sancho Panza) subrayan el tono ridículamente fúnebre.

\section{SANCHO ALCANZA LA ELEGANCIA}

Aquel compromiso moral que plasma el estilo del último capítulo considerado ya se podía apreciar en la discreción con que gobernó Sancho y de la que da fe don Quijote, una vez pasada la vorágine del gobierno, cuando ya están de vuelta y el escudero responde al requerimiento del caballero para que se azote con un bellísimo y discreto parlamento ${ }^{27}$, de tinte estoico, que arranca con una velada referencia a las cuatro pasiones (en cursiva):

- No entiendo eso - replicó Sancho-: solo entiendo que en tanto que duermo ni tengo temor ni esperanza, ni trabajo ni gloria; y bien haya el que inventó el sueño, capa que cubre todos los humanos pensamientos, manjar que quita la hambre, agua que ahuyenta la sed, fuego que calienta el frío, frío que templa el ardor y, finalmente, moneda general con que todas las cosas se compran, balanza y peso que iguala al pastor con el rey y al simple con el discreto. Sola una cosa tiene mala el sueño, según he oído decir, y es que se parece a la muerte, pues de un dormido a un muerto hay muy poca diferencia.

-Nunca te he oído hablar, Sancho - dijo don Quijote-, tan elegantemente como ahora; por donde vengo a conocer ser verdad el refrán que tú algunas veces sueles decir: «No con quien naces, sino con quien paces». (II, 68, 1289$1290)^{28}$.

${ }^{27}$ «Sancho, por la comunicación con Don Quijote, llega a hablar con discreción (era la virtud por excelencia del cortesano, o más bien suma de virtudes), y don Quijote matiza su lengua caballeresca con los viejos refranes castellanos y con las expresiones más típicas de la lengua coloquial. La lengua de la cultura y la lengua del pueblo se funden en una realización superior: la lengua del Quijote» (Rosenblat, 1971: 62). Sobre la discreción en general, Egido (1997).

${ }^{28}$ Ya lo había señalado anteriormente: «—Cada día, Sancho — dijo don Quijote-, te vas haciendo menos simple y más discreto» (II, 12, p. 785); «cuando pienso que se va a despeñar de tonto, sale con unas discreciones que le levantan al cielo» (II, 32, p. 986); - Muy filósofo estás, Sancho - respondió don Quijote-, muy a lo discreto hablas. No sé quién te lo enseña» (II, 66 p. 1275). 
Hay que entender elegancia en su sentido literal: «mesura en el lenguaje, usando términos propios, sin afectación, y estilo corriente y terso» (Covarrubias), que vendría a ser la correspondencia estilística de la discreción. Don Quijote, en recíproca correspondencia, reconoce la que prestan algunos refranes de su escudero.

\section{REFERENCIAS BIBLIOGRÁFICAS}

Allen, John Jay (1979): Don Quixote: Hero or Fool? A Study of Narrative Technique, Gainesville, University Press of Florida.

ARTAZA, Elena (2006): «Los estilos retóricos en los discursos de los personajes literarios», en C. Baranda y A. Vian, eds., El personaje literario y su lengua en el siglo XVI, Madrid, Universidad Complutense, pp. 41-63.

AVAlle-ArCE, Juan Bautista (1976): «Don Quijote» como forma de vida, Valencia, Fundación Juan March-Castalia.

AZAuSTRE, Antonio (1996): Paralelismo y sintaxis del estilo en la prosa de Quevedo, Santiago de Compostela, Universidad.

BAÑEZA, Celso (1989): «Refranes de origen bíblico en Cervantes», Anales Cervantinos, XXVII, pp. 45-77.

BLASCO, Javier (1989): «La compartida responsabilidad de la "escritura desatada" del Quijote», Criticón, XLVI, pp. 41-62.

CANTERA ORTIZ DE URBINA, Jesús (2005): Refranero latino, Madrid, Akal.

CASALDUERO, Joaquín (1975): Sentido y forma del «Quijote» (1605-1615), Madrid, Ínsula.

Cervantes, Miguel de (2004): Don Quijote de la Mancha. Francisco Rico et al., eds., Barcelona, Galaxia Gutenberg.

ClOSE, Anthony (1994): «Cervantes's Aesthetics of Comic Fiction and His Concepto of "la verdad de la historia"», The Modern Language Review, LXXXIX, pp. 88-106.

DíaZ MARROQUín, Lucía (2008): La retórica de los afectos, Kassel, Reichenberger.

EGIDO, Aurora (1992): «Temas y problemas del Barroco español», en F. Rico, dir., Historia y Crítica de la Literatura española. 3/1, Barcelona, Crítica, pp. 1-48.

- (1996): «De La lengua de Erasmo al estilo de Gracián», en La rosa del silencio. Estudios sobre Gracián, Madrid, Alianza, pp. 17-47.

- (1997): Introducción a Baltasar Gracián, El discreto, Madrid, Alianza.

FERnÁNDEZ GÓMEZ, Carlos (1962), Vocabulario de Cervantes, Madrid, RAE.

FORRADELLAS, Joaquín (2005): «Don Quijote entre el libro y la historia», Boletín de la Biblioteca Menéndez Pelayo, LXXXV, pp. 273-294.

ForCiONE, Alban K. (1988): «Cervantes en busca de una pastoral auténtica», Nueva Revista de Filología Hispánica, XXXVI, pp. 1011-1043.

GARCía LÓPEZ, Jorge (2001): «El estilo de una corte: apuntes sobre Virgilio Malvezzi y el laconismo hispano», Cuaderns d'Italià, VI, pp. 155-169.

GarCía MATAMOROS, Alfonso (1570): De tribus dicendi generibus sive de recta informandi styli ratione comentarius, Alcalá de Henares, Andrés Angulo. 
GutiéRrez CuAdrado, Juan (1993): «Sobre algunos desdoblamientos léxicos del siglo XV» en Estudios en honor de José Mondéjar, Salamanca, Universidad, pp. 331-345.

- (2004): «La lengua del Quijote: rasgos generales» en Cervantes 2004 II, pp. 843-881.

- (2005): «Arcaísmos y otros “-ismos”: La selección léxica en el Quijote», Boletín de la Real Academia Española, LXXXV, pp. 335-374.

HATZFELD, Helmut (1972): El «Quijote» como obra de arte del lenguaje, Madrid, RFE.

LAPESA, Rafael (1980): Historia de la lengua española, Madrid, Gredos.

LAUSBERG, Heinrich (1983): Manual de retórica literaria, Madrid, Gredos, 3 vols.

LIDA, Ma Rosa (1956): La visión del trasmundo en las letras hispanas, en H. R. Patch, El otro mundo en la literatura medieval, México, FCE, pp. 371-449.

LÓPEZ GRIGERA, Luisa (1994): «Sobre el realismo literario del Siglo de Oro», en La retórica en la España del Siglo de Oro, Salamanca, Universidad, pp. 133-139.

- (1998): «Quintiliano y la selección estilística en el Renacimiento español», en T. Albadalejo et al., eds., Quintiliano: historia y actualidad de la retórica, Calahorra, Instituto de Estudios Riojanos, 3 vols., I, pp. 185-201.

MARASSO, Arturo (1954): Cervantes. La invención del «Quijote», Buenos Aires, Hachette.

Maravall, José Antonio (1976): Utopía y contrautopía en el «Quijote», Santiago, Pico Sacro.

MENÉNDEZ PIDAL, Ramón (1991): La lengua castellana en el siglo XVII, en R. Lapesa (pról.), Madrid, Espasa-Calpe.

MONER, Michel (1994): «La descente aux enfers de Don Quichotte: fausses chroniques et textes typhes avec quelques énigmes a clè», en F. Cerdan, ed., Hommage à Robert Jammes, Toulouse, Universidad, 3 vols., III, pp. 849-863.

Morreale, Margarita (1959): Castiglione y Boscán: El ideal cortesano en el Renacimiento español, Madrid, Real Academia Española.

PerCas de PONSETI, Helena (1975): Cervantes y su concepto del arte, Madrid, Gredos.

PESET, José Luis (2010): Las melancolías de Sancho. Humores y pasiones entre Huarte y Pinel, Madrid, Asociación Española de Neuropsiquiatría.

RicO, Francisco (2012): Il romanzo ovvero le cose della vita, Turín, Aragno.

RiLEY, Edward C. (1990): Introducción al «Quijote», Barcelona, Crítica.

- (2001): «Una cuestión de género» [1981], en La rara invención. Estudios sobre Cervantes y su posteridad literaria. Barcelona: Crítica, pp. 185-202.

Rosenblat, Ángel (1971): La lengua del «Quijote», Madrid, Gredos.

SERÉS, Guillermo (1997): La traducción en Italia y España durante el siglo XV. La «Ilíada en romance» y su contexto cultural, Salamanca, Universidad.

SPITZER, Leo (1955): «Perspectivismo lingüístico en el Quijote», en Lingüística e historia literaria, Madrid, Gredos, pp. 135-187.

URBINA, Eduardo (1982): «Sancho Panza a nueva luz: ¿tipo folklórico o personaje literario?», Anales Cervantinos, XX, pp. 93-101.

- (1991): El sin par Sancho Panza, Barcelona, Anthropos.

- (1994): «"En alas del deseo": el motivo de los altibajos en Don Quijote», Indiana Journal of Hispanic Literatures, II, pp. 87-104. 